\title{
A ATUAÇÃO DO PEDAGOGO NOS SERVIÇOS SOCIOASSISTENCIAIS
}

\author{
THE PEDAGOGUE'S PERFORMANCE IN SOCIO-ASSISTANCE SERVICES
}

\author{
EL DESEMPEÑO DEL PEDAGOGO EN SERVICIOS DE SOCIO ASISTENCIA
}

\author{
Ana Lucia Ferreira Silva1 \\ Marleide Rodrigues da Silva Perrude ${ }^{2}$ \\ Paula Bortolozo Boaventura ${ }^{3}$
}

\begin{abstract}
RESUMO
O artigo trata da atuação do Pedagogo nos espaços socioassistenciais, na perspectiva da educação não formal e debate sua participação neste contexto. Parte da seguinte indagação: qual o papel do pedagogo no âmbito das ações socioeducativas postuladas pela política de Assistência Social? A discussão é realizada em uma abordagem qualitativa por meio de revisão bibliográfica e análise documental sobre 0 espaço de educação não formal e seu processo de desenvolvimento. Tem como base bibliográfica, os estudos de Coombs (1976), Gohn (2020; 2016), Schmidt e Silva (2015) e Vieira (2011) e análise dos seguintes documentos: a Lei Orgânica da Assistência Social (LOAS) (BRASIL, 1993), Política Nacional de Assistência Social (PNAS) (BRASIL, 2004), Tipificação Nacional dos Serviços Socioassistenciais (BRASIL, 2009), Norma Operacional, Cadernos de Orientação Técnica e Normativas do Sistema Único da Assistência Social (SUAS). Define a política supracitada para melhor compreensão dos espaços e equipamentos socioassistenciais. Situa as ações socioeducativas no campo da política da Assistência Social nos serviços executados em seus equipamentos e o papel do Pedagogo nestes espaços, considerando seu processo de formação. Conclui, destacando os trabalhos pedagógicos que competem aos pedagogos nos espaços dos serviços socioassistenciais, considerando sua especificidade socioeducativa e sua atuação nesses serviços.
\end{abstract}

PALAVRAS-CHAVE: Serviços socioassistenciais. Educação não formal. Atuação do pedagogo.

\section{ABSTRACT}

The article deals with the role of the Pedagogue in socio-assistance spaces from the perspective of nonformal education and discusses the role of the pedagogue in this context. The discussion starts from the following question: what is the role of the pedagogue within the scope of the socio-educational actions postulated by the Social Assistance policy? The discussion is carried out in a qualitative approach through bibliographic review and documentary analysis of the non-formal education space and its development process. It has as a bibliographic base the studies of Coombs (1976) Gohn (2016; 2020), Schmidt and Silva (2015) and Vieira (2011) and analysis of the following documents: the Organic Law of Social Assistance (LOAS) (BRAZIL, 1993), National Social Assistance Policy (PNAS) (BRASIL, 2004), National Type of Social Assistance Services (BRASIL, 2009), Operational Norm, Technical Guidance and Regulatory Notebooks of the Unified Social Assistance System (SUAS). Defines the aforementioned policy for a better understanding of socio-assistance spaces and equipment. It situates the socio-educational actions in the field of Social Assistance policy in the services performed in its equipment and the role of the Pedagogue in these spaces, considering their training process. It concludes by highlighting the pedagogical work competent to pedagogues in the spaces of social assistance services, considering their socio-educational specificity and their performance in these services.

KEYWORDS: Social assistance services. Non-formal education. Performance of the pedagogue.

\section{RESUMEN}

El artículo aborda el papel del pedagogo en los espacios socio-asistenciales desde la perspectiva de la educación no formal y analiza el papel del pedagogo en este contexto. La discusión parte de la siguiente pregunta: ¿cuál es el papel del pedagogo en el ámbito de las acciones socioeducativas que postula la 
política de Asistencia Social? La discusión se realiza con un enfoque cualitativo a través de la revisión bibliográfica y el análisis documental del espacio de educación no formal y su proceso de desarrollo. Tiene como base bibliográfica los estudios de Coombs (1976) Gohn (2016; 2020), Schmidt y Silva (2015) y Vieira (2011) y el análisis de los siguientes documentos: la Ley Orgánica de Asistencia Social (LOAS) (BRASIL, 1993), Política Nacional de Asistencia Social (PNAS) (BRASIL, 2004), Tipo Nacional de Servicios de Asistencia Social (BRASIL, 2009), Norma Operativa, Orientaciones Técnicas y Cuadernos Regulatorios del Sistema Único de Asistencia Social (SUAS). Define la mencionada política para un mejor conocimiento de los espacios y equipamientos socio-asistenciales. Sitúa las acciones socioeducativas en el ámbito de la política Asistencial en los servicios realizados en su equipamiento y el rol del Pedagogo en estos espacios, considerando su proceso de formación. Se concluye destacando la labor pedagógica que compete a los pedagogos en los espacios de los servicios de asistencia social, considerando su especificidad socioeducativa y su desempeño en estos servicios.

PALABRAS CLAVE: Servicios de asistencia social, educación no formal. Actuación del pedagogo.

\section{INTRODUÇÃO}

O objetivo deste trabalho é analisar as ações socioeducativas ${ }^{4}$ situadas no âmbito das políticas de Assistência Social e discutir a atuação do pedagogo neste contexto. Trata-se de pesquisa amparada em abordagem qualitativa, de natureza bibliográfica e análise documental, cujo problema norteador tem origem em nossas práticas profissionais, e pretende responder à seguinte questão: qual o papel do pedagogo no âmbito das ações socioeducativas postuladas pela política de Assistência Social?

Justifica-se este estudo tendo em vista a necessidade de pesquisas dessa natureza, considerando-se que, na atualidade, a presença do pedagogo no campo da Assistência Social tem sido cada vez mais requerida em função de propostas e encaminhamentos explicitados no campo das políticas sociais.

Destaca-se que a temática aqui tratada leva em consideração os cenários político, econômico e social, os quais influenciam e determinam as políticas públicas e sociais. Tal conjuntura, em especial a partir dos anos de 1990 com a reforma empreendida pelo Estado brasileiro, pautada em princípios neoliberais, irá conformar o quadro relativo às políticas, em especial as sociais, bem como o agravamento da questão social no país.

O ponto de partida para as discussões que se seguem encontra respaldo na Constituição Federal (BRASIL, 1988) e no Estatuto da Criança e do Adolescente (BRASIL, 1990), enquanto instrumentos normativos fundamentais no sentido da luta e garantia de direitos de crianças e adolescentes, em especial, aqueles em situação de vulnerabilidade social.

\footnotetext{
4 O termo socioeducativo é tomado como qualificador da ação, designando um campo de aprendizagem voltado para o desenvolvimento de capacidades substantivas e valores éticos, estéticos e políticos a fim de promover 0 acesso e processamento de informaç̃oes, a convivência em grupo e a participação na vida pública. (SÃO PAULO, 2007, p. 10)
}

Revista de Ciências Humanas, Frederico Westphalen - RS, v. 22, n.2, p. 194-215, maio/ago. 2021.

Recebido em: 10/05/2021 $\quad$ Aceito em: 21/06/2021


Posterior a estes, para embasamento técnico teórico e prático mais específicos da política de Assistência Social, apontam-se a Lei Orgânica de Assistência Social (LOAS) promulgada em 1993; a Política Nacional de Assistência Social instituída em 2004; o Sistema Único de Assistência Social implantado em 2011 e as decorrentes Normas Operacionais, os Cadernos de Orientações Técnicas, Normativas, Notas Técnicas e demais orientações, recomendações e atualizações da referida política. Destaca-se, neste processo, a efetivação da garantia dos direitos fundamentais dos indivíduos e suas famílias, numa contextualização do atendimento com foco na matricialidade sociofamiliar ${ }^{5}$, uma vez que, para a política de Assistência Social, faz-se necessário o trabalho com a família, grupo social primário a que a criança e o adolescente pertencem para prevenção, enfrentamento e superação das vulnerabilidades sociais.

Trata-se de estudo que pretende subsidiar e fortalecer a atuação do pedagogo no âmbito de trabalhos socioassistenciais e contribuir com embasamento teórico para as ações desenvolvidas por este profissional no campo da Assistência Social, sem desconsiderar as especificidades relativas ao conjunto de conhecimentos que alicerçam sua formação profissional.

\section{SITUANDO A EDUCAÇÃO NÃO FORMAL}

A discussão acerca da educação não formal e, em decorrência, a atuação do pedagogo nestes espaços, tem sido cada vez mais abordada, no entanto, sua inclusão, ainda recente, na pauta educativa tem trazido diferentes interpretações, incompreensões e incongruências. Neste sentido, a fim de evitarmos dispersões relativas ao termo, trataremos, num primeiro momento, de situar esta questão, ou seja, de estabelecer nosso entendimento acerca do termo educação não formal, cuja historicidade tem origem nos anos de 1960, período de grandes mudanças educacionais promovidas por reformas no campo da educação.

Sobre sua origem, destaca-se que uma primeira definição foi apresentada por Combs (1976), em livro intitulado "A crise mundial de educação", e apontava, em sua perspectiva, os problemas concernentes à educação, bem como possíveis ações e possibilidades visando ao desenvolvimento econômico e humano. 0 autor, ao situar as ações relativas à educação não formal naquele momento histórico, constatava que os objetivos destas atividades "[...] são pouco

\footnotetext{
5 Matricialidade sociofamiliar, em conformidade com a Política Nacional da Assistência Social - PNAS (Brasil, 2004, p.40) se refere "[...] à centralidade da família como núcleo social fundamental para a efetividade de todas as ações e serviços da política de assistência social".
} 
claros, as clientelas indefinidas e a responsabilidade de sua manutenção e administração, dividem-se entre dezenas de entidades públicas e privadas" (COOMBS, 1976, p.198).

No que respeita à coordenação das ações e execução das atividades, estas tinham características bem variadas entre países industrializados e em desenvolvimento, tendo como justificativa as necessidades específicas do ensino não formal de cada localidade, o que mostrou o primeiro indicativo teórico da adequação de modelos não formais de educação, como consequência da complementação necessária para a formação do capital humano. Coombs (1976) apresentava argumentos favoráveis à organização legal da educação não formal como subárea do sistema educativo, devendo, portanto, ser enquadrada nas políticas do Estado. Em sua perspectiva, a ausência de instrumentos normativos que pudessem aferir não apenas a qualidade, como também a responsabilidade nas ações no campo não formal, oferecia indicativos de que a falta de planejamento e de dados específicos da efetividade dos programas e projetos da área, especialmente nos países mais pobres, garantia apenas uma pequena parcela dos recursos educacionais direcionados à educação não formal. Para o autor, o grande problema enfrentado pelos países mais pobres, assim como pelos países ricos seria "[...] a falta de meios organizacionais para enquadrar o ensino não-formal no planejamento educacional pois este se tem limitado ao ensino formal e, muitas vezes, sem alcançar todas as suas partes" (COOMBS, 1976, p.205). Outro aspecto importante destacado por Combs (1976) diz respeito ao planejamento, visto que, sem um planejamento global "[...] não se tem base racional para 0 estabelecimento de prioridades, alocação de parcos recursos, distribuição equilibrada de responsabilidades entre ensino formal e o não-formal naquelas áreas em que ambos atuam" (COOMBS, 1976, p.205).

Coombs (1976) alerta para a compreensão da educação não formal enquanto atividades que se organizam intencionalmente e com propósitos claros de alcançar determinados objetivos educacionais e de aprendizagem ${ }^{6}$. Em estudos posteriores, esta proposição é ampliada e, em publicação de 1974, Coombs e Ahmed (1974 apud TRILLA, 2008, p. 68), afirmam que a educação não formal se refere a: "[...] toda a atividade organizada, sistemática, educativa, realizada fora do marco do sistema oficial, para facilitar determinados tipos de aprendizagem a subgrupos específicos da população [...]". Trilla (2008), em discussão sobre a educação não formal, irá defini-la como o conjunto de processos, meios e instituições específica e diferencialmente concebidos em função de objetivos explícitos de formação ou instrução, não diretamente voltados ao sistema educacional regular de ensino.

6 Em nosso entendimento, esta análise se faz de extrema importância tendo em vista os desdobramentos e implicações pedagógicas advindos desta afirmação, os quais serão tratados adiante.

Revista de Ciências Humanas, Frederico Westphalen - RS, v. 22, n.2, p. 194-215, maio/ago. 2021. 
Ainda que mudanças tenham ocorrido tanto no campo teórico quanto no campo das práticas relativas à educação não formal, desde os primeiros escritos de Combs nos anos de 1960, é possível afirmar que mudanças vêm ocorrendo em cada período histórico, impulsionadas, em especial, por determinantes impostos pela própria sociedade no que se refere a aspectos pontuais e imediatos e também por ações no campo político e ideológico, como no caso do Brasil, com aproximações a determinados setores do Estado e, desde meados dos anos de 1990, conforme análise de Gohn (2005), que afirma que, a partir de mudanças ocorridas na economia global, iniciadas na década de 1990, passou-se a valorizar os processos de aprendizagem em grupos e a dar-se grande importância aos valores culturais que articulam as ações individuais. Também afirma que a atuação da educação não formal não foi imposta apenas pelo plano econômico, mas também, pela contribuição e influência de organizações como a ONU e a Unesco. Silva (2011) afirma que a educação não formal nesse período passa a ser impulsionada por ações do terceiro setor, sem desconsiderar as ações empreendidas pelos organismos internacionais que perceberam neste campo, uma possibilidade de formação humana complementar, uma base para a ampliação e manutenção do capital social e, também, de formação do capital humano.

A educação não formal no Brasil ainda é um campo em construção ${ }^{7}$, conforme assevera Gohn (2016), e, para melhor designá-la, precisamos distingui-la daquilo que ela não é, ou seja, alguns autores a tratam como se ela fosse sinônimo de educação informal ${ }^{8}$. Com a finalidade de demarcação de sentido e significado, em conformidade com as análises elaboradas por Gohn (2016), na educação informal, os agentes educadores são os pais, a família, os amigos, os colegas de escola, a igreja, a mídia, ocorrendo nos mais diversos espaços, como na casa, na rua, no bairro, no clube. Por seu intermédio, o sujeito desenvolve hábitos, atitudes, modos de pensar, ou seja, a educação informal trata da socialização dos sujeitos. Já a educação formal diz respeito à forma organizada e estruturada de como a educação escolar é realizada. Ela ocorre em espaços próprios (escolas) que são instituições regulamentadas por lei, certificadoras e

\footnotetext{
7 Discussão esta corroborada por Garcia (2009), que afirma que a educação não formal não é um conceito pronto e acabado e que, por isso, sua definição está sendo criada, produzida e recriada. Enfatiza, ainda, que o papel acerca da função e seu espaço como "não escolar" precisa ser considerado tendo em vista seu papel político e social na legitimação de saberes.

8 De acordo com Trilla (2008), atribui-se a Combs (1968) não apenas a criação/uso de termo educação não formal, como também o reconhecimento e a popularização da concepção de outras formas e meios educativos desenvolvidos fora da escola, com objetivos educativos. De início, o autor não trazia a diferenciação entre as terminologias - informal e não formal -, utilizando as duas de maneira simultânea, como se fossem sinônimos, sendo que apenas mais tarde Combs, juntamente com Ahmed (1974), em importante e significativa obra, irão trazer à luz a diferenciação entre as três modalidades: formal, informal e não formal.
} 
organizadas por meio de diretrizes nacionais, sendo seus responsáveis diretos, os professores. No caso da educação não formal, esta, por sua vez,

[...] designa um processo com várias dimensões, tais como: a aprendizagem política
dos direitos dos indivíduos enquanto cidadãos; a capacitação dos indivíduos para o
trabalho, por meio da aprendizagem de habilidades e/ou desenvolvimento de
potencialidades; a aprendizagem e exercício de práticas que capacitam os indivíduos
a se organizarem com objetivos comunitários, voltadas para a solução de problemas
coletivos cotidianos; a aprendizagem de conteúdos que possibilitem que os
indivíduos façam uma leitura do mundo do ponto de vista de compreensão do que se
passa ao seu redor; a educação desenvolvida na mídia e pela mídia, em especial a
eletrônica etc. (GOHN, 2016, p. 60)

Neste trabalho, para fins de alcance de seu objetivo, trataremos da discussão da educação não formal, tendo como ponto de referência o trabalho realizado no campo das ações socioeducativas, situadas enquanto ações relativas ao espaço da educação não formal. As ações socioeducativas são aqui compreendidas como práticas que são construídas por meio de processos educativos diferenciados, não vinculados ao sistema formal de ensino. Contribuem para o desenvolvimento pessoal e social de seus participantes (crianças e adolescentes), por meio de atividades formativas complementares, as quais auxiliam o desenvolvimento de conhecimentos, atitudes e habilidades visando ao enriquecimento da criança e do adolescente, ampliando suas vivências e experiências, complementando conhecimentos já trazidos por meio da convivência familiar e suas experiências culturais. As ações socioeducativas permeiam a política da Assistência Social e ofertam à população um conjunto de oportunidades de aprendizagem que promove, entre outros aspectos, a autoestima, a autoconfiança, fortalecimentos de vínculos comunitários, dentre outras capacidades.

Sobre a educação não formal, cabe registrar que, na atualidade, as considerações trazidas por Combs nos anos de 1970 ainda estão presentes em muitos países, sendo possível afirmar que, desde as questões maiores relativas a planejamento e destinação de recursos, até as relativas a instrumentos normativos visando à avaliação da qualidade do trabalho desenvolvido e à responsabilidade nas ações no campo não formal, ainda não encontra uma planificação. No Brasil, cabe destacar, não há (nem houve até o presente momento) uma política específica para as ações desenvolvidas no campo educativo não formal. As ações implementadas sob a designação de "não formal" nunca encontraram um campo próprio, organizado enquanto sistema, ou seja, não há uma política expressa para as ações neste campo. 
Feitas estas considerações, destaca-se que a educação não formal a que se faz referência neste trabalho diz respeito a ações socioeducativas desenvolvidas por diferentes instituições (públicas ou privadas sem fins lucrativos), as quais, por estarem atreladas ao campo da Assistência Social, são normatizadas e regidas pela política deste campo, buscando a garantia de vida digna e inclusão social, sendo que tais ações são destinadas a populações pertencentes a territórios socialmente vulneráveis. Para efeitos deste estudo, tratar-se-á de ações socioeducativas destinadas a crianças e adolescentes em situação de vulnerabilidade social. Parte-se da compreensão de que a educação não formal é:

[...] um processo sociopolítico, cultural e pedagógico de formação para a cidadania, entendendo o político como a formação do indivíduo para interagir com o outro em sociedade. Ela designa um conjunto de práticas socioculturais de aprendizagem e produção de saberes, que envolve organizações/instituições, atividades, meios e formas variadas, assim como uma multiplicidade de programas e projetos sociais. A educação não formal, não é nativa, ela é construída por escolhas ou sob certas condicionalidades, há intencionalidades no seu desenvolvimento, o aprendizado não é espontâneo, não é dado por características da natureza, não é algo naturalizado. 0 aprendizado gerado e compartilhado na educação não formal não é espontâneo porque os processos que o produz têm intencionalidades e propostas. A educação não formal diz respeito à formação do ser humano em geral, é conquista, é direito social de todos(as) (GOHN, 2020, p. 12)

Em conformidade com o exposto, por educação não formal compreende-se as ações desenvolvidas a partir de uma intencionalidade educativa, as quais não correspondem às estabelecidas pelo processo de escolarização formal que ocorrem nos estabelecimentos de ensino tradicionais e oficiais, sendo as escolas e demais instituições de ensino que apresentam caráter formal, regidas por instituições superiores, certificadoras de titularidades e por uma legislação nacional que normatiza critérios e procedimentos de ensino e avaliação. De acordo com Gohn (2016), a educação não formal atua sob outro enfoque, o qual toma como prioritária as categorias espaço e tempo, pelo fato, em especial de não apresentar um currículo com conteúdo e temas definidos a priori.

\section{POLÍTICA DE ASSISTÊNCIA SOCIAL E AÇÕES SOCIOEDUCATIVAS}

Considerando os aspectos abordados no tópico anterior relativos à educação não formal, a discussão que segue tem como foco situar as ações socioeducativas no campo da política da Assistência Social. A temática referente às ações socioeducativas tem tido visibilidade em políticas, programas e projetos de governo, sendo estas vinculadas a conceitos como inclusão, 
promoção social e protagonismo, os quais estão relacionadas à Assistência Social ${ }^{9}$ e à Política Nacional da Assistência Social em vigor, as quais apontam a importância das ações socioeducativas. Conforme estudos de Schmidt e Silva (2015, p. 87), "A partir dos anos 2000, a Política de Assistência Social assumiu papel central nas estratégias governamentais" e tem como objetivo articular as ações educativas e atendimentos socioassistenciais, de acordo com a Lei Orgânica da Assistência Social (LOAS, 1993). Prevê ações socioeducativas voltadas para a faixa etária de 6 a 17 anos, as quais visam a proteção, socialização e 0 fortalecimento de vínculos familiares e comunitários.

A Política Nacional de Assistência Social (PNAS) (BRASIL, 2005) é organizada por graus de complexidade relativos à proteção, por decorrência do impacto de riscos, seja no indivíduo, seja em sua família, e deve contar com a rede socioassistencial, com base no território, a qual:

[...] constitui um dos caminhos para superar a fragmentação na prática dessa política, o que supõe constituir ou redirecionar essa rede, na perspectiva de sua diversidade, complexidade, cobertura, financiamento e do número potencial de usuários que dela possam necessitar (BRASIL, 2005, p. 92).

Os serviços socioassistenciais são aqueles ofertados pelo Sistema Único de Assistência Social (SUAS). Segundo a Tipificação Nacional dos Serviços Socioassistenciais e a Política Nacional de Assistência Social, estes serviços são organizados por níveis de proteção e complexidade: Proteção social básica e Proteção social especial - média e alta complexidade. Em todos os níveis de proteção e complexidade, é possível, e muitas vezes já existente, a atuação do pedagogo para organização e execução de atividades socioeducativas e de articulação intersetorial10, com vistas a garantir a proteção integral a crianças e adolescentes em seus direitos fundamentais, preconizada no Estatuto da Criança e do Adolescente (ECA).

\footnotetext{
9 "A Assistência Social é uma política pública; um direito de todo cidadão que dela necessitar. Ela está organizada por meio do Sistema Único de Assistência Social (Suas), presente em todo o Brasil. Seu objetivo é garantir a proteção social aos cidadãos, ou seja, apoio a indivíduos, famílias e à comunidade no enfrentamento de suas dificuldades, por meio de serviços, benefícios, programas e projetos. Sistema Único de Assistência Social (SUAS) é um sistema público que organiza os serviços de Assistência Social no Brasil. Com um modelo de gestão participativa, ele articula os esforços e os recursos dos três níveis de governo, isto é, municípios, estados e a União, para a execução e o financiamento da Política Nacional de Assistência Social (PNAS), envolvendo diretamente estruturas e marcos regulatórios nacionais, estaduais, municipais e do Distrito Federal". Informações obtidas no endereço eletrônico: https://www.gov.br/cidadania/pt-br/acesso-a-informacao/acoes-programas; em 17 de fevereiro de 2020.

10 "[...] Assistência Social, enquanto política pública que compõe o tripé da Seguridade Social, e considerando as características da população atendida por ela, deve fundamentalmente inserir-se na articulação intersetorial com outras políticas sociais, particularmente, as públicas de Saúde, Educação, Cultura, Esporte, Emprego, Habitação, entre outras, para que as ações não sejam fragmentadas e se mantenha o acesso e a qualidade dos serviços para todas as famílias e indivíduos" (BRASIL, 2005)
}

Revista de Ciências Humanas, Frederico Westphalen - RS, v. 22, n.2, p. 194-215, maio/ago. 2021.

Recebido em: 10/05/2021 $\quad$ Aceito em: 21/06/2021


A Proteção Social Básica, conforme definida na Tipificação Nacional dos Serviços Socioassistenciais, é operacionalizada, com a execução dos serviços: Proteção e Atendimento Integral à Família (PAIF) ${ }^{11}$, executado exclusivamente nos Centros de Referência de Assistência Social (CRAS); Serviço de Convivência e Fortalecimento de Vínculos (SCFV) realizados em grupos socioeducativos ${ }^{12}$ divididos por faixa etária13; Serviço de Proteção Social Básica no Domicílio para Pessoas com Deficiência e Idosas ${ }^{14}$, devendo, ainda, contribuir para promoção de acesso e participação destes nos Serviços de Convivência e Fortalecimento de Vínculos e acessos à rede socioassistencial.

Ainda em conformidade com o documento, a proteção social básica é operada, segundo a Política Nacional de Assistência Social, por intermédio de:

a) Centros de Referência de Assistência Social (CRAS), territorializados de acordo com o porte do município;

b) rede de serviços socioeducativos direcionados para grupos geracionais, intergeracionais, grupos de interesse, entre outros;

c) benefícios eventuais;

d) benefícios de Prestação Continuada;

e) serviços e projetos de capacitação e inserção produtiva (BRASIL, 2005, p. 95-96)

A Proteção Social Especial, por sua vez, conforme descrito na Tipificação dos Serviços Socioassistenciais, é dividida em complexidades. A Proteção Social de Média Complexidade executa: Serviço de Proteção e Atendimento Especializado à Família e a Indivíduos (PAEFI)15, prevendo, como algumas de suas funções essenciais, o trabalho interdisciplinar ${ }^{16}$; Serviço de proteção social a adolescentes em cumprimento de Liberdade Assistida (LA) e de Prestação de Serviços à Comunidade (PSC) ${ }^{17}$, sendo um dos trabalhos essenciais a elaboração de projetos

\footnotetext{
11 "Prevê o desenvolvimento de potencialidades e aquisições das famílias e o fortalecimento de vínculos familiares e comunitários, por meio de ações de caráter preventivo, protetivo e proativo" (BRASIL, 2014, p.12). Prevê, ainda, campanhas socioeducativas, atividades comunitárias, mobilização e fortalecimento da rede de apoio, dentre outros. 12 "[...] de modo a garantir aquisições progressivas aos seus usuários, de acordo com o seu ciclo de vida, a fim de complementar o trabalho social com famílias e prevenir a ocorrência de situações de risco social" (BRASIL, 2014, p.16)

${ }^{13}$ Os grupos do SCFV são divididos em: crianças até 6 anos; crianças e adolescentes de 6 a 15 anos; adolescentes e jovens de 15 a 17 anos; jovens de 19 a 21 anos; adultos de 30 a 59 anos e idosos.

14 "'...] a garantia de direitos, o desenvolvimento de mecanismos para a inclusão social, a equiparação de oportunidades e a participação e o desenvolvimento da autonomia das pessoas com deficiência e pessoas idosas [...]" (BRASIL, 2014, p.25)

15 "Serviço e apoio, orientação e acompanhamento a famílias com um ou mais de seus membros em situação de ameaça ou violação de direitos" (BRASIL, 2014, p. 29)

${ }_{16}$ Por trabalho interdisciplinar, compreende-se aquele realizado em articulação com os profissionais das diferentes áreas e especificidades de atuação da unidade socioassistencial (psicólogo, assistente social, educador social, advogado, etc.), conforme estabelecem os documentos normativos socioassistenciais.

17 "[...] tem por finalidade promover a atenção socioassistencial e acompanhamento a adolescentes e jovens em cumprimento de medidas socioeducativas em meio aberto, determinadas judicialmente." (BRASIL, 2014, p. 34)
} 
sociais; Serviço de Proteção Social para Pessoas com Deficiência, Idosas e suas famílias ${ }^{18}$; Serviço Especializado para Pessoas em Situação de Rua ${ }^{19}$.

A Proteção Social Especial de Alta complexidade, por sua vez, executa: Serviço de Acolhimento Institucional20; Serviço de Acolhimento em República21; Serviço de Acolhimento em Família Acolhedora22; Serviço de proteção em situações de calamidades públicas e de emergência23.

As orientações socioeducativas encontram-se mais voltadas às práticas na Proteção Social Básica, mais especificamente, aos Serviços de Convivência e Fortalecimento de Vínculos (SCFV). Contudo a atuação socioeducativa do profissional de pedagogia pode ser executada em todas as proteções e complexidades ${ }^{24}$ da Política de Assistência Social, uma vez que todas elas atendem o público de crianças e adolescentes e necessitam das atividades e articulações pedagógicas socioeducativas. A insuficiente definição de atividades socioeducativas nos materiais orientadores e norteadores do SUAS, em especial na Proteção Social Especial, o desconhecimento da educação não formal na prática pedagógica e a ausência de conselho de classe de pedagogia para fortalecer a prática profissional, podem ser aspectos influenciadores para estas ações equivocadas na prática socioeducativa.

\section{A ATUAÇÃO DO PEDAGOGO NA EDUCAÇÃO NÃO FORMAL: REFLEXÕES SOBRE AS ESPECIFICIDADES PEDAGÓGICAS NOS SERVIÇOS SOCIOASSISTENCIAIS}

Ao se considerar a atuação do pedagogo nos espaços socioassistenciais, vale lembrar os princípios teóricos e metodológicos que sustentam a prática deste profissional, para que

\footnotetext{
18 "Serviço para oferta de atendimento especializado a famílias com pessoas com deficiência e idosos com algum grau de dependência, que tiveram suas limitações agravadas por violações de direitos [...]" (BRASIL, 2014, p. 37) 19 "Serviço ofertado para pessoas que utilizam as ruas como espaço de moradia elou sobrevivência. Tem a finalidade de assegurar atendimento e atividades direcionadas para 0 desenvolvimento de sociabilidades [...]" (BRASIL, 2014, p. 40)

$20 \mathrm{O}$ acolhimento institucional é organizado nas modalidades: crianças e adolescentes; adultos e famílias; mulheres em situação de violência; jovens e adultos com deficiência; idosos. "Acolhimento em diferentes tipos de equipamentos, destinado a famílias e/ou indivíduos com vínculos familiares rompidos ou fragilizados, a fim de garantir proteção integral" (BRASIL, 2014, p. 44)

21 "[...] oferece proteção, apoio e moradia subsidiada a grupo de pessoas maiores de 18 anos em estado de abandono, situação de vulnerabilidade e risco pessoal e social, com vínculos familiares rompidos ou extremamente fragilizados [...]" (BRASIL, 2014, p. 51)

22 "[...] acolhimento de crianças e adolescentes, afastados da família por medida de proteção, em residência de família acolhedoras cadastradas". (BRASIL, 2014, p. 54)

23 "[...] promove 0 apoio e proteção à população atingida por situações de emergência e calamidade pública [...]". (BRASIL, 2014, p. 57)

24 Proteção Social Básica e Proteção Social Especial de Média ou Alta Complexidade.
} 
equívocos sobre as suas atribuições não desvirtuem seu trabalho ou the imponham funções que descaracterizem suas atribuições profissionais.

É pertinente iniciar a discussão, buscando elementos nas diretrizes do Curso de Pedagogia, nos artigos $4^{\circ}$ e $5^{\circ}$ da Resolução CNE/CP n. 01/2006, que expõem as atribuições do curso de Licenciatura de Pedagogia e relatam a ampliação da formação e atuação do pedagogo. A atuação do Pedagogo é realizada em "áreas nas quais sejam previstos conhecimentos pedagógicos". Estas Diretrizes ampliam o conceito de docência, reconhecendo a participação do Pedagogo na organização e gestão de sistemas e instituições de ensino". Neste contexto, a docência não se restringe ao ato de "dar aulas".

Vieira (2011, p. 132) destaca que o "docente formado deverá estar preparado para desenvolver outros trabalhos de natureza educativa", sendo que a docência

[...] tomada como eixo norteador da formação do professor, do gestor e do intelectual, entendido como produtor de conhecimento. A docência apresenta-se, conforme assinalado, como uma 'docência alargada', extrapolando as atividades de ensino-aprendizagem em sala de aula. (VIEIRA, 2011, p. 132)

O sentido da docência alargada, ampliada, aberta e dilatada possibilita ao pedagogo ampliar a atuação profissional e se "articula à ideia de trabalho pedagógico, a ser desenvolvido em espaços escolares e não escolares" (VIEIRA, 2011, p 136).

Buscando explicitar a dimensão da formação deste profissional, o parágrafo único do documento (BRASIL, 2006) destaca que:

As atividades docentes também compreendem participação na organização e gestão de sistemas e instituições de ensino, englobando:

I - planejamento, execução, coordenação, acompanhamento e avaliação de tarefas próprias do setor da Educação;

II - planejamento, execução, coordenação, acompanhamento e avaliação de projetos e experiências educativas não-escolares;

III - produção e difusão do conhecimento científico-tecnológico do campo educacional, em contextos escolares e não-escolares. (BRASIL, 2006, p.02 Igrifos nossos)

Este documento também indica, no Art. $5^{\circ}$, item IV que o egresso do curso de Pedagogia deverá estar apto a:

- trabalhar, em espaços escolares e não-escolares, na promoção da aprendizagem de sujeitos em diferentes fases do desenvolvimento humano, em diversos níveis e modalidades do processo educativo; (BRASIL, 2006, p. 02) 
No Art. $5^{\circ}$, ainda é possível destacar sobre a atuação do profissional pedagogo que este deverá:

\begin{abstract}
XII - participar da gestão das instituições contribuindo para elaboração, implementação, coordenação, acompanhamento e avaliação do projeto pedagógico; XIII - participar da gestão das instituições planejando, executando, acompanhando e avaliando projetos e programas educacionais, em ambientes escolares e nãoescolares;

XIV - realizar pesquisas que proporcionem conhecimentos, entre outros: sobre alunos e alunas e a realidade sociocultural em que estes desenvolvem suas experiências não-escolares; sobre processos de ensinar e de aprender, em diferentes meios ambiental-ecológicos; sobre propostas curriculares; e sobre organização do trabalho educativo e práticas pedagógicas; (BRASIL, 2006, p. 02-03)
\end{abstract}

Diante do exposto, salienta-se que a atuação do pedagogo não se reduz à docência, ou seja, à escola ou à sala de aula. É preciso, então, superar este reducionismo que estreita sua atuação profissional. Os estudos de Libâneo (2002) destacam que a pedagogia se centra em uma reflexão teórica a partir das práticas educativas. Assim, a pedagogia "[...] investiga os objetivos sociopolíticos e os meios organizativos e metodológicos para viabilizar os processos formativos em contextos socioculturais específicos" (LIBÂNEO, 2002, p. 14). Com tal entendimento, 0 autor critica o reducionismo que limita a prática do pedagogo, visto que a atuação do Pedagogo, vai além, portanto, dos muros da escola.

Entretanto, decorrida mais de uma década de aprovação do último marco legal da formação do profissional pedagogo, muitas indagações ainda se colocam para o debate no que se refere à atuação desse profissional em espaços não formais. Afinal, qual o papel do Pedagogo nos espaços de educação formal? Qual o papel do pedagogo nos serviços socioassistenciais? O que faz este profissional? Isto ocorre devido aos limites dos estudos e, também, da formação dos profissionais para atuar neste campo de trabalho, pois a escola ainda tem sido o campo privilegiado de atuação e de reconhecimento de seu lugar, conforme pesquisa de Fireman (2006).

Precisamos desmistificar a ideia de que o pedagogo só atua na escola. Na visão de Libâneo (2001, p, 06), "A idéia de conceber o curso de Pedagogia como formação de professores [...] é muito simplista e reducionista, é, digamos, uma idéia de senso comum". De acordo com o autor, a Pedagogia se ocupa da formação escolar das crianças, "[...] com processos educativos, métodos, maneiras de ensinar", entretanto, Libâneo (2001, p. 06) salienta que a Pedagogia, tem um "[...] significado bem mais amplo, bem mais globalizante. Ela é um campo de conhecimentos sobre a problemática educativa na sua totalidade e historicidade 
e, ao mesmo tempo, uma diretriz orientadora da ação educativa" (grifos nossos). Ainda segundo

0 autor:

Ela tem um caráter ao mesmo tempo explicativo, praxiológico e normativo da realidade educativa, pois investiga teoricamente o fenômeno educativo, formula orientações para a prática a partir da própria ação prática e propõe princípios e normas relacionados aos fins e meios da educação.

Pedagogia é, então, o campo do conhecimento que se ocupa do estudo sistemático da educação do ato educativo, da prática educativa como componente integrante da atividade humana, como fato da vida social, inerente ao conjunto dos processos sociais. Não há sociedade sem práticas educativas.

Pedagogia diz respeito a uma reflexão sistemática sobre o fenômeno educativo, sobre as práticas educativas, para poder ser uma instância orientadora do trabalho educativo. (LIBÂNEO, 2001, p. 06/grifos nossos)

Assim como a educação não pode ser reduzida a ensino, pois é um conceito amplo, polissêmico e histórico, a Pedagogia também não deve ser limitada à ação escolar.

Em resumo, a Pedagogia, mediante conhecimentos cientíicos, filosóficos e técnicoprofissionais, investiga a realidade educacional em transformação, para explicitar objetivos e processos de intervenção metodológica e organizativa referentes à transmissão/assimilação de saberes e modos de ação. Ela visa 0 entendimento, global e intencionalmente dirigido, dos problemas educativos e, para isso, recorre aos aportes teóricos providos pelas demais ciências da educação. LIBÂNEO, 2001, p. 10/grifos nossos).

O pedagogo é o profissional que atua em todos os espaços que requerem um trabalho educativo, ou seja, processos de ensino e aprendizagem, planejamento, gestão e interlocução com as diferentes áreas de conhecimento. Libâneo $(2001, p, 11)$ aprofunda a discussão expondo que:

O pedagogo é o profissional que atua em várias instâncias da prática educativa, direta ou indiretamente ligadas à organização e aos processos de transmissão e assimilação de saberes e modos de ação, tendo em vista objetivos de formação humana previamente definidos em sua contextualização histórica. (LIBÂNEO, 2001, p. 11)

Considerando os espaços de educação não formal e o trabalho pedagógico, há que se considerar que:

[...] há uma diversidade de práticas educativas na sociedade e, em todas elas, desde que se configurem como intencionais, está presente a ação pedagógica. A contemporaneidade mostra uma "sociedade pedagógica", revelando amplos campos de atuação pedagógica. (LIBÂNEO, 2001, p. 12) 
Acerca das ações e práticas educativas intencionais, destaca-se que a intencionalidade educativa é foco de preocupação no campo da educação não formal, conforme abordado inicialmente por Coombs (1976), que, dentre os aspectos destacados, explicita a organização, a intencionalidade e propósitos claros no sentido de alcançar determinados objetivos educativos e de aprendizagem, constituindo-se, tais aspectos, foco de preocupação da educação não formal. Também cabe pontuar que, em sendo o pedagogo o profissional que busca organizar e pensar 0 trabalho pedagógico em diferentes espaços, sua presença se faz, de fato, necessária, tendo em vista o conjunto de conhecimentos que sua formação lhe possibilita em termos de pensar tanto em teorias, quanto em práticas educativas. Tendo em vista a intencionalidade educativa que deve guiar as ações nos diferentes espaços em que são desenvolvidas ações no campo da educação não formal, a presença do pedagogo se faz indispensável e justifica, portanto, a presença deste profissional neste campo, levando-se em conta que a organização do trabalho pedagógico deverá ser norteada a partir de uma intencionalidade educativa.

Outro destaque acerca da intencionalidade educativa dos espaços de educação não formal diz respeito aos propósitos e objetivos das ações neste campo, os quais, considerando suas particularidades de sujeitos (crianças e adolescentes, jovens, adultos, idosos) e diferentes espaços (entidades do poder público, entidades sem fins lucrativos, associações) e atividades/ações desenvolvidas (projetos, oficinas, percursos educativos), evidenciam-se 0 papel das ações desenvolvidas e atividades suplementares às ações, tradicionalmente, realizadas pelo campo escolar. Muitas vezes, estas ações são confundidas com ações apenas complementares às do campo formal/escolar, não se levando em conta que estas, além da intencionalidade educativa, pressupõem o estabelecimento de objetivos, propósitos, enfim, a instauração de uma organização e planejamento das ações considerando as especificidades dos sujeitos, dos espaços e do trabalho a ser desenvolvido, sendo que esta questão precisa ser revista (e aprofundada) considerando os aspectos já apresentados neste estudo.

Neste sentido, a aprendizagem é um processo inerente ao ser humano e pode ocorrer nos três âmbitos: formal, não formal e informal. Desde o nascimento, o ser humano vivencia constantes aprendizados, dos básicos aos mais complexos. Destaca-se, aqui, o contexto da educação no trabalho pedagógico não formal, em que, segundo Gohn (2005), acontece a aprendizagem por meio de práticas sociais, experiências pessoais e coletivas, com conhecimentos gerados pelas vivências e interações interpessoais, sociais, culturais, com trocas simultâneas, em sua maioria em caráter coletivo, grupal. 
Para atuar no espaço de educação não formal, em especial o espaço socioassistencial, o pedagogo precisa dominar um conjunto de conhecimentos que lhe possibilitem desenvolver seu trabalho em qualquer instância.

Sistematizar a metodologia contida nos processos de interação/aprendizagem dependerá de nossa capacidade, enquanto educadores, de entender os sujeitos pensantes/falantes no interior dos processos sociais em movimento, nas organizações etc. Para tanto, é muito importante que saibamos escutar não apenas as falas, mas também os silêncios que acompanham ou interrompem aquelas falas. (GOHN, 2005, p. 107)

Perrude e Silva (2013) asseveram a importância de se observar alguns princípios no que respeita à formação e à atuação do Pedagogo nos espaços de educação não formal. Em seus aspectos gerais, destacam a necessidade de conhecer a realidade da comunidade com a qual irá trabalhar; pensar propostas que contemplem objetivos pedagógicos explícitos com relação ao ato educativo, observação e identificação das necessidades da comunidade envolvida; prever ações sistematizadas e permeadas pela praxis. Ressaltam, ainda, a importância de este profissional ter um compromisso ético e político com a comunidade em que atua e com a luta para manter e conquistar novos direitos, desenvolvendo trabalhos que contemplem o tema cidadania.

Ao se considerar a atuação do pedagogo no âmbito socioassistencial, torna-se imprescindível o conhecimento do contexto social, das vulnerabilidades e especificidades do território e dos indivíduos atendidos, a fim de proporcionar momentos de fortalecimento pessoal e social para o enfretamento das vulnerabilidades e o acesso a ferramentas para sua efetivação, com ações práticas e interdisciplinares. Este trabalho deverá ser pensado em conjunto com os demais profissionais do equipamento socioassistencial em que se realiza 0 trabalho socioeducativo, além de se estabelecer relações com os demais equipamentos socioassistenciais e das diversas políticas públicas, com trabalho que promova mudanças a partir de reflexões e condições de acesso aos direitos fundamentais.

O trabalho do pedagogo em espaço socioassistencial está diretamente relacionado aos processos de formação humana, com vistas à transformação dos sujeitos envolvidos na prática pedagógica.

Apreender a Dimensão Pedagógica do trabalho educativo não-escolar no âmbito das relações contraditórias da sociedade contemporânea é entender as possibilidades históricas de transformação social através do trabalho de elevação cultural e moral dos sujeitos históricos, partindo do pensamento gramsciano, tomar o núcleo do bom senso existente no senso comum e, à luz da natureza de cada espaço de trabalho educativo não-escolar, trabalhar para que as pessoas de uma determinada 
comunidade atendida ou participante daquela instituição ampliem suas possibilidades de atuarem como cidadãos engajados na construção de uma nova hegemonia social. (SÁ, 2000, p. 176-177)

Considerando a amplitude e a complexidade da ação interdisciplinar do trabalho socioeducativo nos serviços socioassistenciais, tem sido recorrente a participação de pedagogos nas equipes técnicas das unidades e execução das atividades socioeducativas com crianças, adolescentes e suas famílias. A atuação do pedagogo nos serviços socioassistenciais e na gestão do Sistema Único da Assistência Social (SUAS) está regulamentada pela Resolução $\mathrm{n}^{\circ}$ 17, de 20 de junho de 2011 do Conselho Nacional dos Direitos da Criança e do Adolescente (CONANDA) ${ }^{25}$, definindo o profissional pedagogo na categoria de profissionais de ensino superior na composição das equipes de referências das unidades e gestão da Política de Assistência Social, indicada na Norma Operacional Básica de Recursos Humanos do SUAS (NOB-RH/SUAS).

Com o desconhecimento da atuação do pedagogo nos espaços não formais, definidos no primeiro item deste artigo, em especial nas unidades que têm como público-alvo crianças e adolescentes, tem sido comum a expectativa de que o profissional de pedagogia realize ações semelhantes às atividades educacionais em espaços formais. Considerando-se que os espaços não formais se diferem dos espaços formais de educação em suas especificidades e objetivos, bem como as descrições dos serviços socioassistenciais supracitados, os quais não fazem referência a atividades educacionais escolares, cabe ao pedagogo a execução de atividades que visem ao fortalecimento de vínculos familiares e comunitários dos indivíduos e famílias, a promoção da proteção e garantia dos direitos fundamentais, por meio de ações integradas com as demais unidades socioassistenciais e políticas públicas, considerando a integralidade e amplitude do desenvolvimento social dos indivíduos.

A oferta de atividades e conteúdos escolares é de competência exclusiva da Política de Educação, não sendo aplicável nas unidades socioassistenciais, qualquer que seja seu público atendido ou especificidade de atendimento.

Ações pontuais ou esporádicas na forma de bailes, festas, atividades físicas, oficinas, passeios e palestras não caracterizam, por si só, os grupos do SCFV. 0 mesmo vale para a promoção de cursos profissionalizantes e para a oferta de apoio escolar/acadêmico, os quais não são de competência da política de assistência social e, por conseguinte, não o são também do SCFV. (BRASIL, 2016, p. 21)

25 Refere-se, neste artigo, a crianças e adolescentes por serem o foco de estudo, contudo, em todos os espaços de atendimento pertencentes à política de assistência social, o pedagogo deve exercer a função socioeducativa e não educacional escolar.

Revista de Ciências Humanas, Frederico Westphalen - RS, v. 22, n.2, p. 194-215, maio/ago. 2021. Recebido em: 10/05/2021 $\quad$ Aceito em: 21/06/2021 
Considerando que a atuação do pedagogo na política de Assistência Social tem caráter articulador, orientador e socioeducativo, foi apresentado, na Introdução deste trabalho, pautado em documento já citado (SÃO PAULO, 2007), o entendimento das autoras acerca do que se entende por atividades socioeducativas, cuja base se ampara em uma compreensão de aprendizagem de valores éticos, estéticos e políticos, em ações desenvolvidas em que são privilegiadas a vivência grupal e a participação na vida pública e na convivência social.

Este mesmo documento descreve as práticas socioeducativas como construção de atividades por meio de processos que não estão vinculados aos níveis de escolarização, ao sistema escolar formal, objetivando e possibilitando, assim, o desenvolvimento social e pessoal dos indivíduos a partir de suas vivências e experiências pessoais, culturais e sociais. Visa também à prevenção de situações violadoras de direitos, à promoção e à garantia dos direitos fundamentais dos indivíduos. Por meio das ações socioeducativas, fazem-se imprescindíveis atividades articuladas com os demais serviços da rede socioassistencial e da rede intersetorial de atendimentos a famílias e indivíduos, em especial a crianças e adolescentes, objeto principal de debate neste artigo.

\section{CONSIDERAÇÕES FINAIS}

A efetivação da superação das vulnerabilidades não acontece de forma isolada, considerando que a vulnerabilidade social e/ou econômica atinge famílias e indivíduos em todos os contextos de suas necessidades, colocando em risco e/ou violando mais de um de seus direitos fundamentais. Desta forma, as atividades socioeducativas integradas com os serviços da política de Assistência Social e das demais políticas públicas, contribuem para a efetivação da prevenção e proteção integral de crianças, adolescentes e suas famílias. Neste aspecto, cabe ao pedagogo da unidade articular ações integradas junto à educação, cultura, esporte, programas de aprendizagem, saúde, e demais unidades que se fizerem necessárias, no âmbito municipal, estadual ou no federal. Tais práticas podem acontecer tanto em grupos, quanto em atendimentos individuais e familiares para orientações, intervenções, articulações e encaminhamentos necessários junto à equipe da unidade.

$\mathrm{Na}$ atuação, mais especificamente com crianças e adolescentes, que estão em idade escolar, faz-se fundamental a articulação intersetorial com as unidades escolares para acompanhamento e realização de ações socioeducativas conjuntas, buscando a prevenção da evasão e a promoção do acesso ao direito à educação. Neste aspecto, cabe, ainda, ao pedagogo atuante na educação não formal, orientações às famílias na garantia e efetivação 
deste direito fundamental de crianças e adolescentes atendidos. Entretanto, não cabe aos profissionais pedagogos a execução ou proposição de momentos, nas unidades socioassistenciais, de realização de tarefas escolares ou oferecimento de atividades de reforço escolar, uma vez que tais ações se referem ao contexto da educação formal, contradizendo as práticas previstas na educação não formal e nos trabalhos socioeducativos exigidos no âmbito da Assistência Social, embora tais práticas ainda sejam observadas nas unidades socioassistenciais de alguns municípios, em especial naquelas que atendem crianças e adolescentes.

A ação pedagógica socioeducativa no trabalho de formação dos sujeitos para a humanização e a emancipação do homem envolve a capacidade de articular valores humanos e, consequentemente, sociais e culturais. Estas ações exigem um trabalho coletivo, cuja especificidade da ação do pedagogo, está centrada nos processos educativos que envolvem formação, trabalho coletivo, planejamento, orientação pedagógica, coordenação de projetos, monitoramento e avaliação, orientações familiares e individuais, além de trabalho articulador para a execução das práticas socioeducativas de forma a contemplar o complexidade do Sistema de Garantia de Direitos da Criança e do Adolescente (SGDCA), previsto na Resolução $n^{0} 113^{26}$ do Conselho Nacional dos Direitos da Criança e do Adolescente (CONANDA), contribuindo para a construção de uma proposta pedagógica que promova a inclusão social e acesso ao conhecimento, nas suas diferentes manifestações, e a participação dos sujeitos.

Para a efetiva atuação socioeducativa no espaços socioassistenciais, torna-se necessário que o profissional tenha a pesquisa como elemento central de sua prática pedagógica, para compreensão de sua prática de forma que ela se torne coerente, coesa, efetiva e vá ao encontro das demandas do trabalho executado, seja nas unidades de Proteção Social Básica nos Serviços do PAIF e SCFV, nas unidades de Proteção Social Especial com orientações e ações para prevenção e superação de situações violadoras de direitos, nas práticas socioeducativas com adolescentes em cumprimento de medida socioeducativa, executando, de fato, a socioeducação, ou, nas práticas com as crianças e adolescentes em Serviços de acolhimento, sejam eles institucionais ou familiares. Para tanto, torna-se essencial que o pedagogo, em sua atuação em espaços de educação não formal, exerça uma ação

26 "Art. $1^{\circ} \mathrm{O}$ Sistema de Garantia dos Direitos da Criança e do Adolescente constitui-se na articulação e integração das instâncias públicas governamentais e da sociedade civil, na aplicação de instrumentos normativos e no funcionamento dos mecanismos de promoção, defesa e controle para a efetivação dos direitos humanos da criança e do adolescente, nos níveis Federal, Estadual, Distrital e Municipal. $§ 1^{\circ}$ Esse Sistema articular-se-á com todos os sistemas nacionais de operacionalização de políticas públicas, especialmente nas áreas da saúde, educação, assistência social, trabalho, segurança pública, planejamento, orçamentária, relações exteriores e promoção da igualdade e valorização da diversidade".

Revista de Ciências Humanas, Frederico Westphalen - RS, v. 22, n.2, p. 194-215, maio/ago. 2021. 
investigativa, pois, sem o conhecimento do contexto em que está envolvido, não é possível 0 desenvolvimento de um trabalho que contribua para a realidade sociocultural e econômica, demandas e vulnerabilidades dos sujeitos.

O Pedagogo, como profissional responsável pelos processos educativos, necessita que seu trabalho, além de articulado e interdisciplinar, seja adequadamente planejado, com objetivos definidos para uma ação efetiva e com significado para o ambiente e pessoas envolvidas.

Dessa forma, a atuação deste profissional na educação não formal, nos espaços socioassistenciais, em sua prática socioeducativa, não pode ser reprodutora da educação formal, ou seja, da educação escolar e seus conteúdos, seja no ensino ou reforço dos mesmos. A prática social da pedagogia está atrelada à educação para promoção de reflexões, promoção da cidadania, garantia de direitos, oferta de ferramentas para mudanças sociais e compreensão política da prática cotidiana dos indivíduos, a fim de promover ações emancipatórias e socialmente fortalecidas.

Conclui-se que o pedagogo contribui com a construção de propostas pedagógicas, que favorecem a defesa e a promoção do direito de crianças, adolescentes e suas famílias a partir de ações de reflexão, acesso aos direitos fundamentais e sua garantia, além de ações preventivas e para superação de situações violadoras de direitos. O desafio proposto é relacionado à formação dos pedagogos nos cursos de Pedagogia e à formação de profissionais que deem conta de atuar em espaços não formais, com competência técnica e compromisso político, levando aos espaços socioassistenciais as possibilidades de atuação do pedagogo, extinguindo as ações de complementaridade da educação não formal às práticas educacionais escolares, buscando 0 fortalecimento das práticas socioeducativas, sejam elas pessoais e/ou coletivas/comunitárias.

\section{REFERÊNCIAS}

BRASIL. Constituição (1998). Constituição da República Federativa do Brasil de 1988. Brasília, DF. Presidência da República, [2016]. Disponível em: <http://www.planalto.gov.br/ccivil_03/Constituicao/Constituiçao.htm>. Acesso em: 21 de fev. 2020.

BRASIL. Estatuto da Criança e do Adolescente. Lei 8069 de 1990 e suas alterações. Disponível em: <http://www.planalto.gov.br/ccivil_03/leis//8069.htm>. Acesso em 20 de fev. 2021.

BRASIL. Lei $n^{0}$ 8.742, de 7 de dezembro de 1993. Disponível em: <http://www.planalto.gov.br/ccivil_03/leis//8742.htm>. Acessado em 14/08/2020.

BRASIL. Norma Operacional Básica: NOB-SUAS. 2012. 
BRASIL. Norma Operacional Básica de Recursos Humanos: NOB-RH/SUAS: Anotada e comentada. 2011.

BRASIL. Política Nacional de Assistência Social: PNAS/2004. 2005. Reimpresso em 2013. BRASIL. Tipificação Nacional dos Serviços Socioassistenciais. 2009. Reimpressão 2014.Diponível em:

<https://www.mds.gov.br/webarquivos/publicacao/assistencia_social/Normativas/tipificacao.pdf>. Acessado em 10/08/2020.

BRASIL. Tipificação Nacional dos Serviços Socioassistenciais. 2009. Reimpressão 2014.Diponível em:

<https://www.mds.gov.br/webarquivos/publicacao/assistencia_social/Normativas/tipificacao.pdf>. Acessado em 10/08/2020.

BRASIL. Caderno de orientações: Serviço de Proteção e Atendimento Integral à Família e Serviço de Convivência e Fortalecimento de Vínculos: Articulação necessária na Proteção Social Básica. Disponível em:

$<$ https://www.mds.gov.br/webarquivos/publicacao/assistencia_social/Cadernos/Cartilha_PAlF_16 05.pdf>. Acessado em 10/08/2020.

BRASIL. Resolução $n^{0} 113$, de 19 de abril de 2006. Conanda. Disponível em: <https://www.mpam.mp.br/attachments/article/1984/Resolu\%C3\%A7\%C3\%A30\%20n\%C2\%BA\% 20113\%20do\%20Conanda.pdf.>. Acesso em 15/08/2020.

BRASIL. Resolução n 17, de 20 de junho de 2011. In: Tipificação Nacional dos Serviços Socioassistenciais. 2009. Reimpressão 2014.Diponível em:

<https://www.mds.gov.br/webarquivos/publicacao/assistencia_social/Normativas/tipificacao.pdf>. Acessado em 10/08/2020.

BRASIL. Resolução CNE/CP 1. Diretrizes Curriculares Nacionais para o Curso de Pedagogia. 2006. Disponível em: < http://portal.mec.gov.br/cne/arquivos/pdf/rcp01_06 .pdf>Acesso em: 23 de fev. de 2016.

COOMBS, Philip Hall. A crise mundial da educação: uma análise de sistemas. São Paulo: Perspectiva, 1976. 2.ed. (Coleção Debates). Tradução de: The world educational crisis.

FIREMAN, Maria Derise. O Trabalho do Pedagogo na Instituição não Escolar. Dissertação de mestrado, Maceió, 2006. Disponível em : <https://cedu.ufal.br/posgraduacao/mestrado-e-doutorado-em-educacao/institucional/dissertacoes/2003-mestrado/mariaderise-fireman>. Acesso em 12 de setembro de 2020.

GARCIA, Valéria Aroeira. A educação não-formal como acontecimento.2009.445p. Tese ( doutorado ) - Universidade Estadual de Campinas, Faculdade de Educação, CAMPINAS, SP. Disponível em: <http://www.repositorio.unicamp.br/bitstream/REPOSIP/251690/1/Garcia_ValeriaAroeira_D.pdf>. Acesso em 24 de abril de 2021. 
GOHN, Maria da Glória. Educação não formal nas instituições Sociais. Revista Pedagógica, Chapecó, v. 18, n. 39, p. 59-75, set./dez. 2016. Disponível em:

<http://dx.doi.org/10.22196/rp.v18i39.3615>. Acesso em 23 de mar. 2020.

GOHN, Maria da Glória. Educação não-formal e cultura política: impactos sobre 0 associativismo de terceiro setor. $3^{a}$ edição. São Paulo: Cortez, 2005.

GOHN, Maria da Glória. Educação não formal: direitos e aprendizagens dos cidadãos(ãs) em tempos do coronavírus. Revista Humanidades e Inovação v.7, n.7.7 - 2020. Disponível em: $<$ https://revista.unitins.br/index.php/humanidadeseinovacao/article/view/3259>. Acesso em: 23 de mar. 2021.

LIBÂNEO, José Carlos. Pedagogia e Pedagogos, para quê? São Paulo: 5. ed. São Paulo: Cortez, 2002.

LIBÂNEO, José Carlos. Pedagogia e pedagogos: inquietações e buscas. Educar, Curitiba, n. 17, p. 153-176. 2001. Editora da UFPR .Disponível em: <https://www.scielo.br/pdf/er/n17/n17a12>. Acesso em 08/08/2020

PERRUDE, Marleide Rodrigues. SILVA, Ana Lucia Ferreira. Atuação do pedagogo em espaços não-formais: algumas reflexões. Revista Eletrônica Pro- docência/UEL. Edição nº 4, vol. 1, juldez. 2013. Disponível em:

<https://www.scielo.br/pdf/er/n17/n17a12http://www.uel.br/revistas/prodocenciafope/pages/arquiv os/Volume4/TEXTO\%205\%20-\%20p.\%2046\%20a\%2056.pdf>. Acesso em 08/08/2020

SÁ, Ricardo Antunes de. Pedagogia: identidade e formação. O trabalho do pedagógico nos processos educativos não-escolares. In: Educar. Curitiba, n. 16, p. 171-180. 2000. Editora da UFPR. Disponível em:

<https://www.scielo.br/j/er/a/whtVxwyZw6V3w7KLTZj863q/?lang=pt\&format=pdf>. Acesso em $08 / 08 / 2020$

SÃO PAULO. Parâmetros socioeducativos: proteção social para crianças, adolescentes e jovens: Igualdade como direito, diferença como riqueza : Caderno 1 : Síntese / CENPEC - São Paulo SMADS ; CENPEC ; Fundação Itaú Social, 2007. Disponível em:

$<$ https://www.sigas.pe.gov.br/files/03282018115835-

acoes.socioeducativas.igualdade.como.direito.diferenca.como.riqueza.pdf>. Acesso em $16 / 08 / 2020$.

SCHMIDT, Janaina Albuquerque de Camargo; SILVA, Mossicléia Mendes da. A assistência social na contemporaneidade: uma análise a partir do orçamento público R. Katál., Florianópolis, v. 18, n. 1, p. 86-94, jan./jun. 2015. Disponível em: <https://www.scielo.br/pdf/rk/v18n1/pt_14144980-rk-18-01-00095.pdf>. Acesso em 24 de abril de 2021.

SILVA, Ana Lucia Ferreira. Orientações da UNESCO para a Educação Não-Formal: Repercussões no contexto brasileiro. Cadernos de Pesquisa. Curitiba, V.6, n.12, 2011, p.103124 
TRILLA, Jaime. A educação não-formal. In: ARANTES, V. (Org). Educação formal e nãoformal. São Paulo: Summus, 2008.

VIEIRA, Suzane da Rocha. Docência, Gestão e Conhecimento: conceitos articuladores do novo perfil do pedagogo instituído pela Resolução CNE/CP N. 01/2006 Revista HISTEDBR On-line. Campinas, n.44. p. 131-155. de: 201 I - ISSN: 1676-2584. Disponível em: $<$ https://periodicos.sbu.unicamp.br/ojs/index.php/histedbr/article/view/8639982>. Acesso em 08/08/2020. 